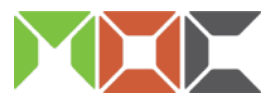

2018 Modular and Offsite Construction (MOC) Summit

(a)

World of Modular, March 22-25

The Diplomat Beach Resort, Hollywood, FL, USA

\title{
IoT-based Inventory Control System Framework for Panelized Construction
}

\author{
Meng WANG ${ }^{1}$, Yongsheng MA ${ }^{2 *}$, Mohammed Sadiq ALTAF ${ }^{3}$ and Mohamed AL-HUSSEIN ${ }^{4}$ \\ ${ }^{1}$ M.Sc. Student, Department of Mechanical Engineering, University of Alberta \\ ${ }^{2}$ Professor, Ph.D., Department of Mechanical Engineering, University of Alberta \\ ${ }^{3}$ Post-doctoral Fellow, Department of Civil \&Environmental Engineering, University of Alberta \\ ${ }^{4}$ Professor, Ph.D., Department of Civil \& Environmental Engineering, University of Alberta \\ "Corresponding author's e-mail: yongsheng.ma@ualberta.ca
}

\begin{abstract}
Modular construction and panelized construction have been promoted and recognized globally as advanced construction techniques. Not only have these construction methods been utilized in the oil and gas industry, but they have also successfully been introduced into the residential construction industry. In North America, the panelized construction technique has become popular particularly for wood-frame wall panels. However, although utilizing this advanced construction method can greatly improve the working environment and productivity, the conventional mentality in construction, which overlooks the value of an automated management system to support offsite prefabrication and onsite installation, hinders its potential. An Internet of Things (IoT)-based management system can capture all dynamic data in real time and effectively synthesize it along the supply chain associated with various types of resources. Eventually, with the assistance of a feature-based modeling method, IoT-based information collection can be merged into an Enterprise Resource Planning (ERP) system. Although highly dynamic market demands result in continual changes in the production plan, schedule, and inventory levels, adopting an IoT-based system accounts for the dynamic changes characteristic of this advanced construction method in order to maximize production. Therefore, in this paper, a conceptual framework for an IoT-based inventory control system is proposed in order to enhance the production and satisfy Just-in-Time inventory principle. IoT-based real-time technology is introduced and the development of supportive software is described. Part of the proposed IoT-based inventory control system is implemented as a case study in a panelized construction manufacturing facility, ACQBUILT, Inc., based in Edmonton, Alberta, Canada.
\end{abstract}

\section{KEYWORDS}

Panelized Construction; Internet of Things (IoT); Radio Frequent Identification (RFID); Barcode; Building Information Modeling 


\section{INTRODUCTION}

Modular construction has been deployed in various applications, such as oil and gas plants, pipeline construction, and residential building construction. Prefabricated construction is a term used to describe the use of factory-produced pre-engineered building units that are delivered to the construction site and assembled as large volumetric or two-dimensional (e.g., panel) components (Pasquire et al., 2002). Compared to traditional stick-built construction for commercial and residential buildings, prefabricated housing construction has become an increasingly sustainable and innovative construction method among homebuilders capable of (i) improving product quality due to a controlled (indoor) construction environment, (ii) increasing productivity, (iii) and reducing waste and construction time. (NAHB) The process of building prefabricated homes, also referred to as panelized home construction (CTC), breaks down the production process into elements such as floor, wall, and roof. These essential elements are manufactured in a fabrication plant and then shipped to the construction site for installation. The prefabricated panels are unique and vary in product design features (e.g., length, window and door type and associated joints, connections). (Liu et al. 2015) Garza-Reyes et al. (2012) compare panelized home construction with conventional stick-built construction, identifying advantages of the prefabricated home process such as a controlled working environment, improved inventory management, and easier implementation of new technology into the process. One of the most notable factors to be considered panelized construction in particular is the cost versus benefits for the company. Although the potential benefits of panelized construction have been gradually drawing the attention of industry, the complexity of the material types and product variability are significant factors that affect the production process. Additionally, despite the associated advantages of advanced construction methods, most construction companies continue to adhere to traditional means of production and inventory control, which is carried out using paper-and-pencil methods to track the necessary information. To help panelized construction companies realize the benefits of this method, an Internet of Things (IoT)-based inventory control system is proposed and a case study is implemented to collect the necessary data in a real-time manner from stock, production line, etc. along the supply chain. This system allows for the continuous collection of real-time data from both the offsite prefabrication facility and the construction site which can then be analyzed and used as an input to ERP system for planning and control purposes. The IoT-based inventory control system comprises a barcode-enabled inventory control, an RFID-enabled wall panel production line control (Wang et al. 2017), and a mobile QR-enabled on-site installation control. Thus, by implementing this integrated system, unnecessary processes can be eliminated and productivity can be improved.

\section{METHODOLOGY}

The overview of the methodology is presented in Figure 1. A BIM model is used at the design stage to aid the homebuyer in selecting and designing their custom home. BIM can be used to generate the preliminary construction schedule based on dynamic real-time information obtained from inventory, offsite production, onsite production, and suppliers. (Liu et al. 2014) Additionally, the BIM model can optimize the material selection and cutting in order to reduce material waste. (Zhao et al. 2015) Barcode technology is used in the IoT-enabled system to track the internal movement of materials, including stock, material receiving and transferring, as well as offsite production operations. RFID technology is utilized to automatically capture the panel location and processing time at each workstation in the prefabrication facility. Material location on the 
production line and daily productivity can be identified through the proposed integrated system with real-time information obtained through IoT-based technologies. Moreover, QR code scans will potentially aid in the control and management of on-site material movement and production productivity, etc. All real-time information can be acquired for multiple objectives and synchronized to a cloud-based central database for the proposed integrated system. This system increases the level of automation of the construction process in both the offsite and onsite environments, such that traditionally manual operations such as recording, data entry, inspection, and counting can be eliminated, thereby improving the accuracy of collected data based on realtime information and further improving productivity and work-in-process inventory in a real-time manner.

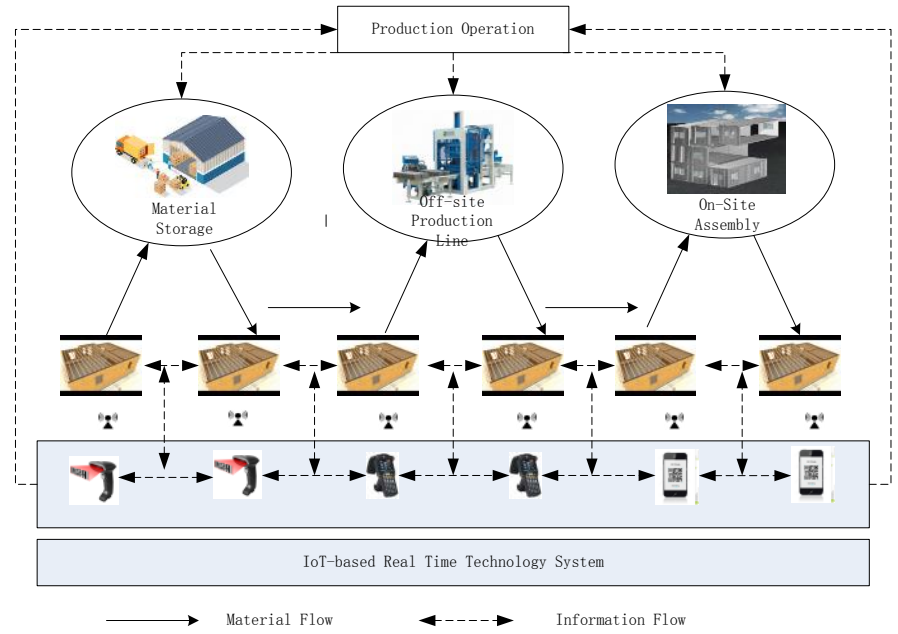

Figure 1. IoT-based system architecture.

With the implementation of the IoT-based inventory control system, all dynamic information flow can be shared and transmitted in a bi-directional manner, unlike the traditional prefabrication environment where all production details are generated from the production plan stage and only flow downstream (following the flow of materials). Traditional prefabrication facilities struggle to accommodate the dynamics of customer demand, which can lead to either material shortage or inventory overstock. Moreover, effective buffer time and real-time feedback between the production operation plan and information flow can be obtained through the IoT-based management system. In addition to production monitoring, analyses such as risk analysis and prediction can be potentially performed using automatically collected real-time information.

\section{Design of RFID Technology}

Figure 2 presents the flowchart of for the RFID system employed in this research. RFID technology collects production data in real-time for the purpose of management and control in the form of data mining, automated production monitoring, and reporting, as well as simulation modeling. RFID technologies include an RFID printer, reader, antenna, and tags. The RFID print files are extracted from a 3D BIM model and supply the printer with the project numbers and names of single-wall panels. Each single-wall panel is assigned a unique ID number, and information is transmitted and stored into a designed central database. Once the operator off-loads the raw material at the first station of the wall-panel production line, the line worker assigns a related RFID tag to each wall panel, and the antenna picks up the signal when the wall panel passes the reader-covered-zone. To 
capture the movement of the wall panels through the production line, antennae are installed at each station to enable the timestamp data to be transmitted to the database.

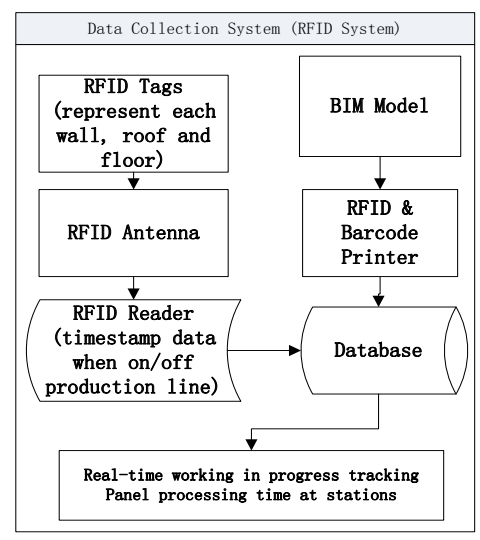

Figure 2. RFID system flowchart.
Program Development Overview

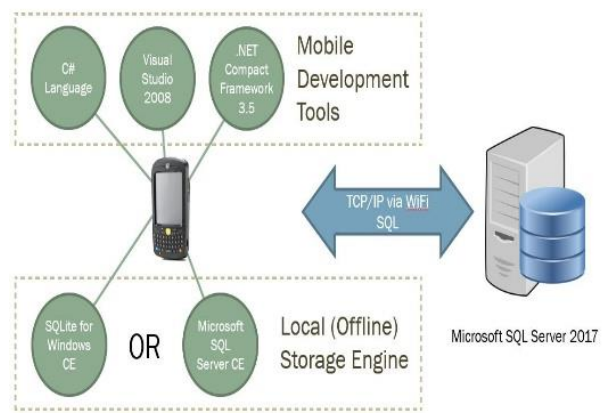

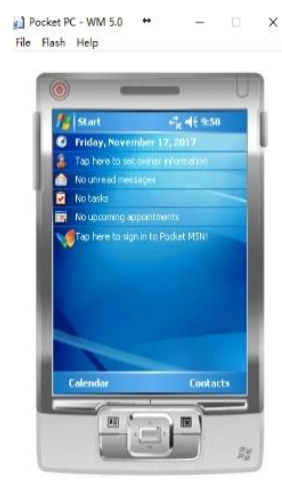

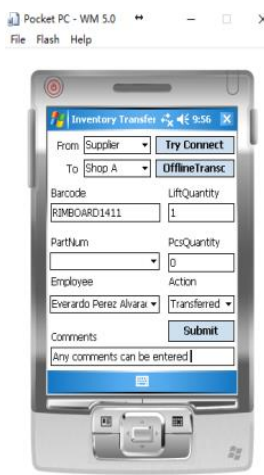

Figure 3. Overview of program development and user interface.

\section{Design of Barcode Technology}

Figure 3 presents an overview of the program development and user interface. The barcode technology stores and transmits the timestamp data into the system database in real time. The IoTbased system consists of five main tables: (1) the action table includes the actions required once the operator has identified and updated the type and quantity of material; (2) the material table automatically provides an abbreviated material name for reference by operators when unique barcode identification is scanned into device; (3) the employee name table keeps track of the name of the employee operating the given device and submits the transactions; (4) the location table contains detailed location information for the purpose of identifying the current location and destination of materials being transferred; (5) the main barcode table receives all information submitted through the IoT-based system in real time. Structured query language (SQL) is used to extract all necessary information from the database in terms of material quantity, material location, etc.

\section{IMPLEMENTATION AND RESULTS}



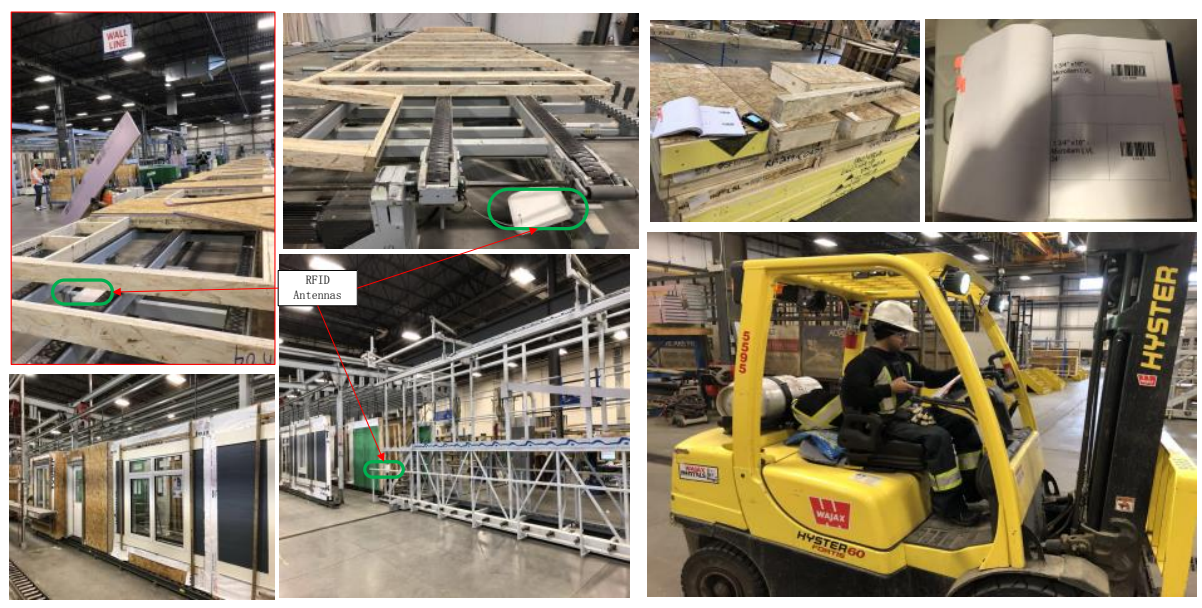

Figure 4. IoT-based technology implementation at ACQBUILT.

The photograph located in the upper-left corner of Figure 4 shows the RFID technology on the framing station. The second upper photograph shows the RFID technology on the transfer cart, where wall panels and sheathing frames that are nailed automatically at the multi-function station get transferred to the window installation line by a transfer cart. The lower-left photograph shows the window/door installation line. After window and door installation, the wall panel is transferred by another transfer cart (lower-right photograph) equipped with RFID to the wall magazine line at the end of the production line for temporary storage. In addition, not only can the RFID system track the timestamp on the production line, but it can also identify the location of the panels in real time. One disadvantage is that the devices need continuous wireless Internet support so that all timestamp data can be captured in real time throughout the prefabrication facility. Whenever the power of the facility shuts down or the wireless network is lost, the RFID system will stop working. For example, in the case study, the wireless Internet range only covers the main office building and production facilities, while the main gate and stock yard are not within the wireless Internet range. Therefore, real-time RFID data collection does not extend to inventory and on-site installation in the case company's current practice. With respect to the absence of RFID for material receiving and transferring from the stock, barcode technology can be combined with RFID on the production line to maintain consistent real-time data. Barcode scanning has gained considerable attention in the areas of inventory and logistics management. A barcode is a machinereadable optical representation of data that can be one-dimensional or two-dimensional and which uniquely defines a specific product. A one- or two-dimensional pre-defined barcode not only can be applied in logistics and inventory management, but it is also potentially useful for on-site installation construction at a later stage due to the advantage of usability in locations with no wireless Internet (unlike RFID, which requires continuous wireless support). Moreover, the implementation of barcodes is less expensive than RFID. Cost is a key reason why barcode development and implementation has been prioritized despite some existing disadvantages of barcode technology, such as that the barcode scanner must be carried by hand and it must be aligned with the pre-defined barcode in order for the device to recognize the code. Although human error is a potential disadvantage of this technology, it is addressed at the case company through training of personnel and the development of a manual on the correct use of the device, as well as modification of the barcode system based on user experience feedback. 


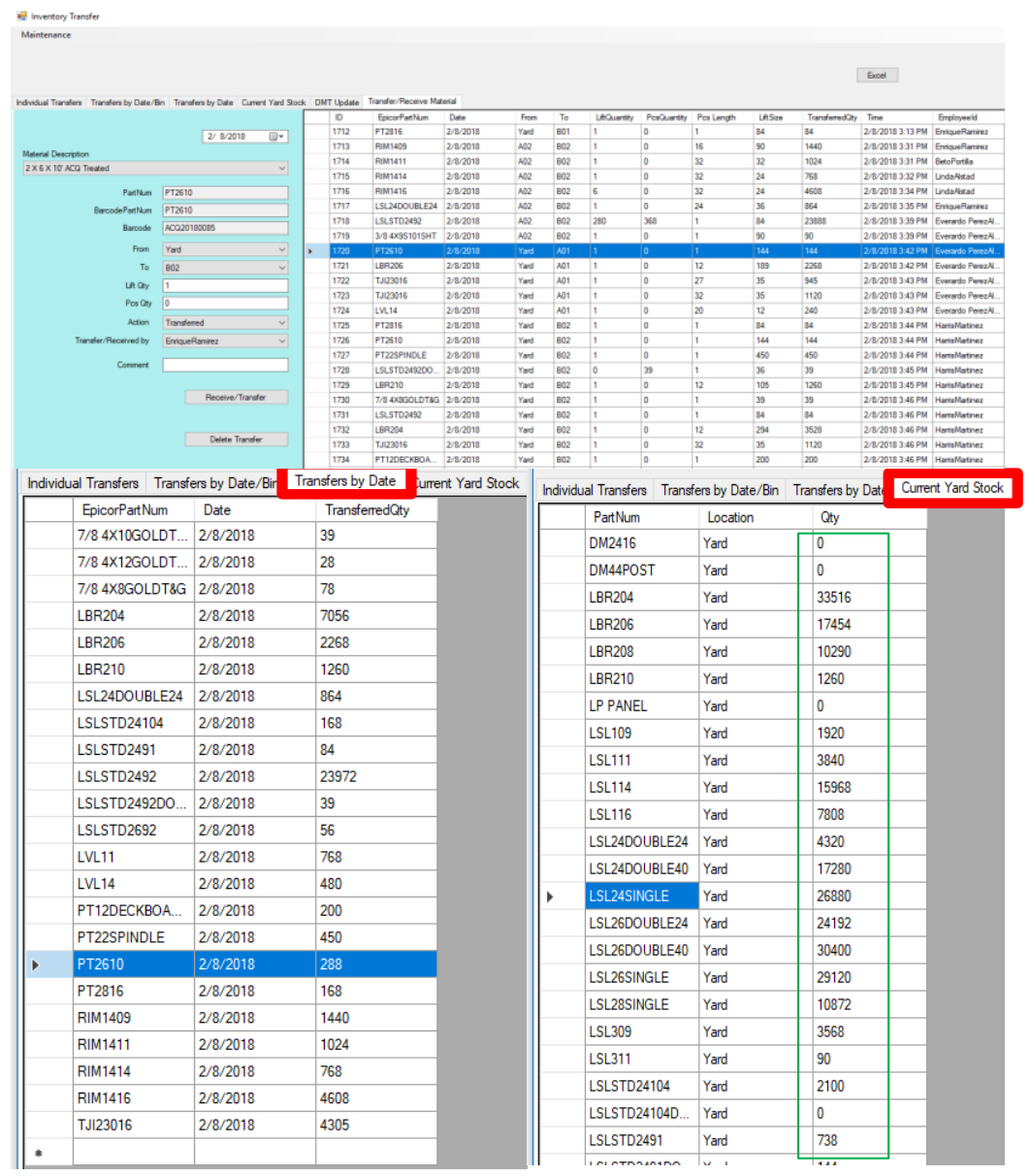

Figure 5. Screenshot of inventory management system interface.

Figure 5 presents the estimators/management view in inventory management. The system was developed and in-use in estimating department. Real-time data collected from the developed technology can be obtained for estimator view and it helps update the current stock quantity automatically. The dynamic data are from IoT-based technology implemented at the case company, tracking the locations of materials. This is in contrast to the traditional method of managing materials, which results in a lag in data availability because the reports and data entry are input manually into the database the following day. Using the inventory management system, the user can calculate the remaining quantity of materials in order to make decisions in regard to material purchasing in real-time. Also, the production schedule can be optimized using the IoTbased inventory control system. With all the formatted data collected, they system can extract all required information from the inventory management system in a excel format, and then insert all data back into ERP system.

\section{Cost-benefit Analysis}

To verify the cost effectiveness of the partially developed IoT system, a cost-benefit analysis is performed for barcode technology. The analysis is based on current market conditions in Alberta, Canada, in terms of working hours, salary rate, and initial setup costs. As determined in the analysis, in the existing practice one office employee spends three hours per day entering 
production data from the previous day collected in paper form. Based on an hourly rate of $\$ 25$ (Canadian dollars) and 260 days of production data (five days per week $\times 52$ weeks in a year), the cost to the case company of carrying out this simple data entry task is approximately $\$ 19,500$ per year. We can assume that associative general $\&$ administrative expenses and office supply costs related to this particular task amount to approximately $\$ 300$ per year. Meanwhile, assuming that each operator spends half an hour filling out paper data forms, that there are two operators working a given shift, and that the hourly rate of pay for operators is $\$ 27$ the cost of operators filling out the data forms is $\$ 7,020$ per year. In summary, in the existing approach without IoT and RFID/barcode technology the simple activities of filling out the data forms and entering data into the system manually cost the company approximately $\$ 26,820$ per year.

The initial setup cost for two barcode devices and a wireless network is assumed to be $\$ 2,000$. Thus, implementing the IoT-based system results in a savings of $\$ 24,840$ per year. This savings is expected to be even more significant in cases where housing demand increases as well as for projects with longer duration. With the implementation of the proposed system, the authors expect to see additional savings for the case company due to the IoT-based system. Similar benefits can be expected for other panelized construction companies.

\section{CONCLUSION}

This study presents a conceptual framework of an IoT-based information sharing system for a panelized construction homebuilder. In recent years, the lack of information sharing has been a significant challenge that has hindered the advancement of advanced construction methods. IoTbased technologies can obtain real-time production information and material tracking, thereby eliminating the need for traditional data collection for decision-making purposes and historical data storage. The IoT-based control system under development in this research, a portion of which is implemented in a case study as described above, comprises GPS, sensors, data storage, and machine learning and decision support tools. Such a system not only can effectively improve the efficiency of panelized construction, but it can also create a common link for users from all aspects along the supply chain both internally and externally. By adopting IoT-based technologies, buffer time, inventory level, productivity, re-work, and so on can all be easily identified and addressed accordingly. The proposed framework consists of an internal system and an external system. The internal IoT-based inventory control system includes barcode-controlled inventory, RFIDcontrolled production line, and mobile QR code-controlled production. The IoT-based barcode and RFID system have been developed and implemented in a case panel prefabrication facility as described above. The proposed external system to be developed in future research is a cloud-based system used to facilitate information sharing with suppliers and other stakeholders.

\section{ACKNOWLEDGEMENTS}

We gratefully acknowledge the financial support of the Natural Sciences and Engineering Research Council of Canada (NSERC).

\section{REFERENCES}


Garza-Reyes, J. A., Oraifige, I., Soriano-Meier, H., Forrester, P. L., and Harmanto, D. (2012). "The development of a lean park homes production process using process flow and simulation methods.” Journal of Manufacturing Technology Management, 23(2), 178-197.

Liu, H., Altaf, M. S., Lei, Z., Lu, M., and Al-Hussein, M. (2015). “Automated production planning in panelized construction enabled by integrating discrete-event simulation and BIM." Proceedings of the International Construction Specialty Conference, Vancouver, BC, Canada, Jun. 8-10.

Liu, H., Lei, Z., Li, H.X., and Al-Hussein, M. (2014). An automatic scheduling approach: Building information modeling-based on-site scheduling for panelized construction. In Proceedings of the Construction Research Congress, pp. 1666-1675.

National Association of Home Builders, Fast facts for panelized homes, Retrieved October 24, 2013, from, 2009. http://www.nahb.org/generic.aspx?genericContentID=10310. NAHB

Pasquire, C.L., and Gibb, A.G.F. (2002). Considerations for assessing the benefits of standardization and pre-assembly in construction. Journal of Financial Management of Property and Construction, 7(3), 151-161.

The Canadian Timber Company (2015). What is Panelized Construction? [Internet]. Ontario, Canada: The Canadian Timber Company; 2007 [cited 2015 Dec 20]. Available from: http://www.canadiantimber.ca/build panelized.html. CTC

Wang, Z., Hu, H., and Zhou, W. (2017). RFID Enabled Knowledge-Based Precast Construction Supply Chain. Computer-Aided Civil and Infrastructure Engineering, 32(6), 499-514. doi:10.1111/mice. 12254

Zhao, H., Liu, H., and Al-Hussein, M. (2015). Automation of quantity takeoff for modular construction. Proceedings, 2015 Modular and Offsite Construction (MOC) Summit and 1st International Conference on the Industrialization of Construction (ICIC), Edmonton, $\mathrm{AB}$, Canada, May 19-21, 458-465. 